\title{
ЗЧЕПЛЕННЯ МЕТАЛЕВОЇ АРМАТУРИ КЛАСУ А500С 3 БЕТОНОМ ПРИ ПОВТОРНИХ НАВАНТАЖЕННЯХ
}

\author{
ADHESION OF A500C METAL REINFORCEMENT \\ WITH CONCRETE FOR REPEATED LOADS
}

Чапюк О.С., к.т.н., доц., Пахолюк О.А., к.т.н., доц., Кислюк Д.Я., к.т.н., доц., Задорожнікова І.В., к.т.н., доц., Гришкова А.В., асп., (Луцький національний технічний університет, м. Луцьк)

Chapiuk O., Ph.D., Assoc., Pakholyuk O., Ph.D., Assoc., Kislyuk D., Ph.D., Assoc. Prof., Zadorozhnikova I, Ph.D., Assoc., Grishkova A., PhD stud. (Lutsk National Technical University, Lutsk)

Отримано результати експериментальних досліджень зчеплення стержнів арматури класу А500С, зароблених в бетонні призми різного перерізу при малоциклових навантаженнях. Встановлено, щзо величина бетонної оболонки не суттєво впливає на величину граничного руйнівного зусилля витягання арматурного стержня при одноразовому навантаженні $і$ значно більше впливає на величину зміщення арматури. Повторні навантаження впливають $і$ на граничні зусилля $i$ на повні взаємні зміщення стержнів відносно бетонної оболонки.

The most important factor that ensures the joint work of reinforcement and concrete in reinforced concrete structures is the adhesion at the contact between them. It is achieved by gluing reinforcement with cement stone, friction between the surfaces of these materials, as well as engaging the protrusions on the surface of the rods. In road and civil construction in the manufacture of reinforced concrete structures is most used reinforcing steel sickle profile. Until the 1990s, traditional profile reinforcement was used, which differs significantly from the newer crescent-shaped reinforcement. An important feature of the interaction of reinforcement with concrete is the mutual displacement, as a result of which there may be a redistribution of forces. These areas are called reinforcement anchoring zones. Destructive processes develop within a layer of very small thickness (several millimeters). The redistribution of forces between concrete and reinforcement depends most on the deformation of the contact layer, rather than the size of the shell [2]. Virtually all reinforced concrete structures, especially road structures, are subjected to significant re-loading during operation, the impact of which on the joint work of concrete and reinforcement has been very little studied. This article investigates the features of the coupling of reinforcing bars of class A500C depending on the length of 
the anchoring under the action of repeated loads. It is established that the size of the concrete shell does not significantly affect the value of the ultimate destructive force of elongation of the reinforcing rod at a single load and significantly more affects the amount of displacement of the reinforcement. Repeated loads affect both the ultimate forces and the complete mutual displacements of the rods relative to the concrete shell.

Ключова слова: арматурні стержні серповидного профілю, А500С, зчеплення, бетонна призма, поперечний переріз, зони анкерування, повторні навантаження, проковзування стержнів.

Keywords: reinforcing rods of a crescent-shaped profile, A500C, coupling, concrete prism, cross section, anchoring zones, repeated loadings, sliding of rods.

Вступ. В житловому і дорожньому будівництві при виготовленні залізобетонних конструкцій у нас і за кордоном вже більше 20 -ти років використовується арматурний прокат серповидного профілю. В Україні застосування такої арматури регламентовано ДСТУ 3760:2006 і спеціально розробленими відповідними рекомендаціями. Але особливості роботи такої арматури в з/б конструкціях досліджено недостатньо, особливо при повторних навантаженнях.

Постановка проблеми і задачі дослідження. Особливістю взаємодії арматури класу А500С з бетоном є взаємні зміщення, внаслідок яких може відбуватися перерозподіл зусиль. Ті ділянки, на яких видно перерозподіл зусиль називаються зонами анкерування. При дослідженні їх зчеплення приймається модель «арматура / контактний шар/ бетон». Суть цієї моделі полягає у тому, що має виділятися контактний шар, до якого якраз i відноситься бетон, який знаходиться у зоні найвищих напружень. Вважається, що деструктивні процеси розвиваються у межах шару малої товщини, близької до кроку виступів на арматурних стержнях (декілька міліметрів) [1]. Ймовірно, перерозподіл зусиль між арматурою і бетоном в найбільше залежить від деформацій контактного шару, а не загалом, оболонки. А це означає, що вплив бетонної оболонки на зчеплення 3 арматурою А500С практично й не досліджувався.

Практично всі залізобетонні конструкції у під час експлуатації піддаються різним повторним навантаженням, а вплив їх на зчеплення бетону з арматурою досліджувався дуже мало [2].

Виходячи 3 наведеного, у даній роботі вирішено дослідити особливості зчеплення арматури класу А500С 3 бетоном залежно від величини самої бетонної оболонки при дії як одноразових так і повторних навантажень. 
Матеріали дослідних зразків. Дослідні зразки виготовлялися у вигляді бетонних призм трьох видів зі сторонами 100, 150 та 200 мм, по центру яких розташовувався арматурний стержень діаметром 16 мм класу A500C. Довжина анкерування рівна 10d, відповідно, висота всіх бетонних призм становила 160 мм (Рис.1). Тимчасовий опір розриву арматури $f_{f d}=$ 621 МПа; умовна межа текучості $f_{p}=497$ МПа та модуль пружності $E_{f}=$ $2 * 10^{5}$ МПа. Всього виготовили 18 зразків, які поділили на дві групи: перша досліджувалася одноразовим короткочасним навантаженням до руйнування, щоб взнати граничне напруження (призми ПК); друга (призми ПП) повторним навантаженням на 10 циклів. Після позначення призм цифрами було вказано розміри поперечного перерізу призм.

Рис. Загальний вигляд дослідних зразків.

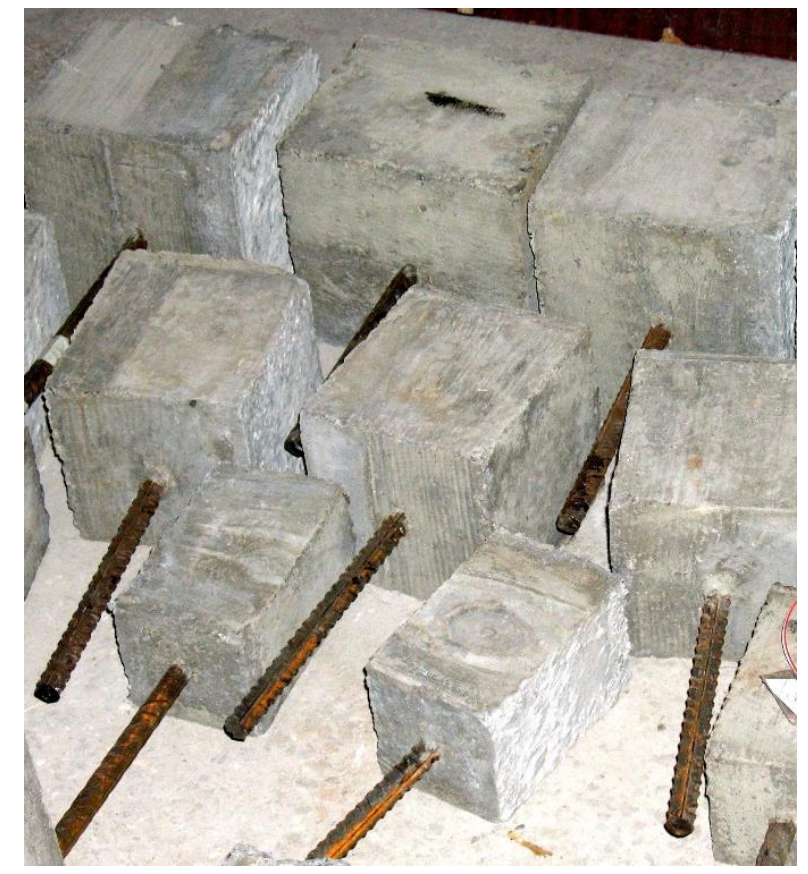

Рис.1. Загальний вигляд дослідних зразків

Методика випробування бетонних призм. Зчеплення арматури 3 бетоном досліджували шляхом висмикування арматурного стержня 3 бетонної призми в розривній гідравлічній машині (рис. 2). Навантаження до стержня давали невеликими кроками, рівними 1,0 кН. Також, вимірювали проковзування незавантаженого верхнього кінця арматурного 
стержня відносно верхнього торця бетонної призми годинниковим індикатором i деформації стержня по довжині 3 нижнього боку тензометром Гугенбергера з базою 20 мм, де ціна поділки 0,001 мм [3].

Зразки ПП 10 разів піддавалися повторним навантаженням до рівнів $\eta_{\text {сус }}=0,6$, а на одинадцятому зразки довантажували до руйнування. За граничний руйнівний стан зчеплення арматури і бетону ми приймали зусилля, коли проковзування ненавантаженого кінця стержня відносно торця бетонної призми було $\delta_{u}=0,2$ мм.

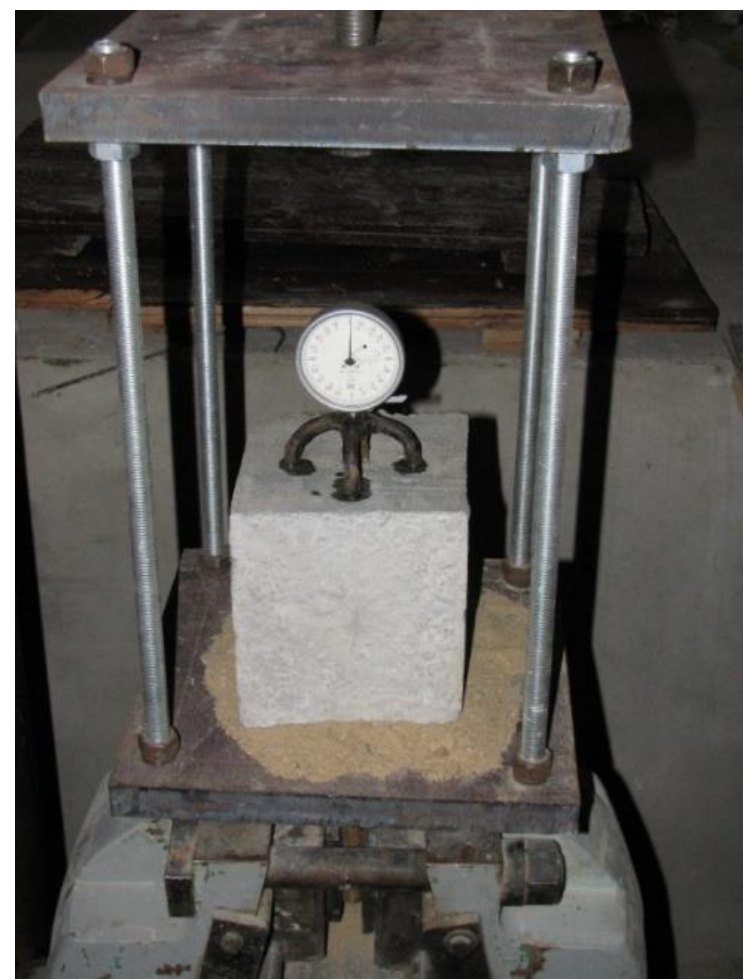

Рис. 2. Дослідження зразків на зчеплення арматури з бетоном в розривній машині УММ-50

Результати досліджень. Перші зміщення вільного кінця стержнів, яке дорівнювало $\delta=0,001$ мм у зразках ПК10 (розмір сторони призми 10 см) зафіксовано при напруженні в арматурному стержні $f_{y d}=49,8 \mathrm{MПа,} \mathrm{а} \mathrm{в}$ зразках ПК15 і ПК20 - відповідно при $f_{y d}=59,7$ і 89,9 МПа. Тобто, зі збільшенням об'єму оболонки збільшується зусилля, за якого 
спостерігається початок зміщення стержнів. При подальшому навантаженні зміщення стержнів в усіх зразках поступово збільшувалися і при напруженні $f_{y d}=199$ МПа середнє значення по зразкам склало $\delta=$ 0,012; 0,036 і 0,009 мм.

Висмикування арматурних стержнів з бетонних призм у трьох зразках ПК10 відбулося при навантаженнях $P_{u}=55,56$ і 60 кН. Середнє значення $P_{u m}=57 \kappa \mathrm{і} \mathrm{коефіцієнті} \mathrm{мінливості} \mathrm{7,5 \% ,} \mathrm{якому} \mathrm{відповідає} \mathrm{середнє}$ значення напруження $f_{y d m}=288,5$ МПа. Схожа мінливість результатів спостерігалася у всіх зразках-близнюках, що досліджувались, а це свідчить про хорошу достовірність отриманих даних. В середньому, руйнування зразків ПК15 відбулося при $P_{u m}=58 \mathrm{\kappa H}$, а ПК20 зs стороною 200мм - при $P_{u m}=59,5 \mathrm{\kappa H}\left(f_{y d m}=295,6 \mathrm{MПа}\right)$. Отже, було помічено, що в межах досліджуваних розмірів зразків (100мм, 150мм, 200мм), об'єм оболонки практично не впливає на силу висмикування з неї стержнів.

У зразках ПК15 руйнівне зусилля визначено за величиною проковзування стержня, що рівне $\delta_{u}=0,2$ мм. У зразках ПК20 перед висмикуванням нами було зафіксовано велике, але ще не 0,2 мм зміщення всередньому $\delta=0,165$ мм. А у всіх зразках ПК10 перед руйнуванням були зафіксовані найменші зміщення стержнів, які перед руйнуванням в середньому були $\delta=0,072$ мм. Отже, на ці зміщення впливають поперечні зусилля, i вони залежать від розмірів бетонної оболонки, та співвідношення між жорсткістю арматурного стержня та бетонної призми. В зразках ПК10 жорсткість бетонної призми виявилася меншою за жорсткість самого стержня і тому оболонка у поздовжньому напрямку в більшій мірі деформувалася разом із стержнем. Саме тому зміщення арматурного стержня виявилося набагато меншим, ніж у зразках ПК15 i ПК20. У зразках ПК20 зміщення верхнього кінця стержня відбулося меншим, ніж у зразках ПК15, і це можна пояснити більшим опором самої бетонної оболонки поперечним зусиллям.

Щодо повторних навантажень, то при розвантаженні спостерігалися залишкові проковзування, які в зразках ПП10, ПП15 і ПП20 після першого циклу склали 53,4\%, 63,6\%, 57,5\%, відповідно. При наступних циклах повторних навантажень спостерігалося незначне збільшення сумарних i залишкових зміщень кінців стержнів.

Після 10 однакових циклів повторних навантажень повні проковзування арматурних стержнів у зразках ПП-10, ПП-15 і ПП-20 зросли відповідно до $\delta=0,017 ; 0,088$ і 0,073, що відповідно на 86,1; 196,5 і 220 \% більше, ніж їхні максимальні зміщення на 1-му циклі. Отже, повні зміщення збільшилися практично в 3 рази, i при цьому разом зі збільшенням поперечних розмірів бетонної призми збільшуються i проковзування.

На останньому одинадцятому циклі усі зразки доводились до руйнування (Рис. 3). Середнє значення зусилля витягання стержнів у 
зразках ПП-10 склало $P_{u m}=60$ кН $\left(f_{y d}=297,5\right.$ МПа), що на 3,3 \% більше, ніж в зразках ПК-10. Руйнуваня зразків ПП-15 і ПП-20 відбулося при дії зусиль відповідно $P_{u m}=52$ і 53 кН $\left(f_{y d}=258,7\right.$ і 261,2 МПа). При цих навантаженнях (зусиллях) у зразках ПП-15 повне середнє проковзування стержнів склало $\delta=0,205$, а в зразках ПП-20 - $\delta=0,245$ мм.

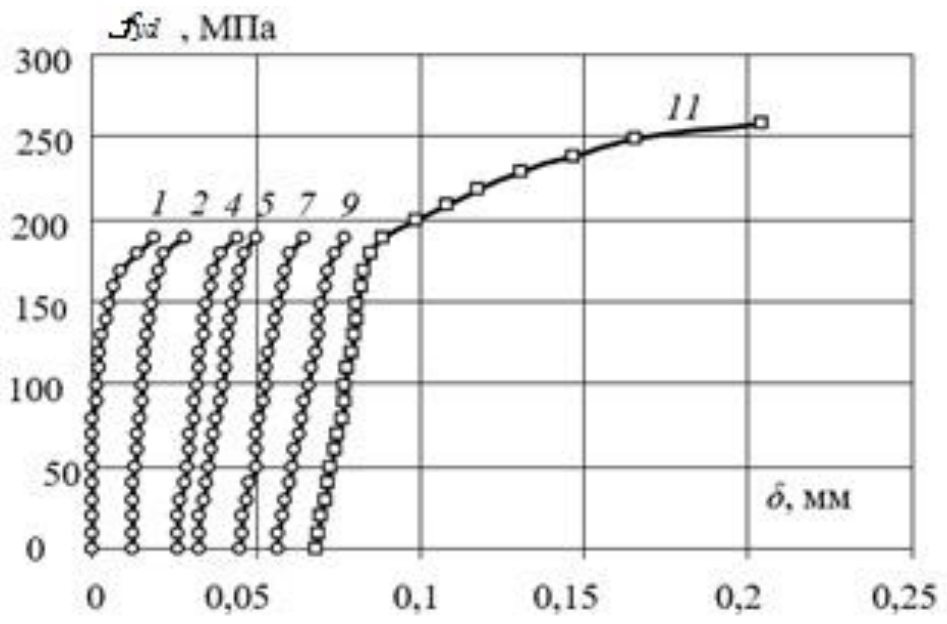

Рис. 3. Проковзування арматури в бетоні $\delta$ при повторних навантаженнях зразків ПП15 (цифрами вказані номери циклів навантаження)

Беручи до уваги залишкові деформації у зразках ПП, то перед руйнуванням їхні повні зміщення досягли значення $\delta=0,208$ мм. Якщо порівнювати зі зразками ПК-15 і ПК-20, то руйнівне зусилля після 10-ти повторних навантажень у зразках ПП-15 зменшилося на $12,3 \%$, а у зразках ПП-20 - на 14,3 \%. Отже, на руйнівне зусилля витягання арматурних стержнів впливає відношення їх жорсткості до жорсткості бетонної призми.

\section{Висновки}

1. Величина поперечного перерізу бетонної призми в межах розмірів, які досліджувалися, майже не впливає на величину руйнівного максимального зусилля витягання арматурного стержня класу А500С.

2. Розміри поперечного перерізу бетонної призми впливають на величини взаємних зміщень, а сам характер впливу залежить від співвідношення жорсткості бетонної оболонки до жорсткості арматурного стержня. 
3. Повторні навантаження в межах 10-ти циклів до рівня 0,6 від руйнівного зусилля призводять до збільшення в 3 рази повних зміщень вільних кінців арматурних стержнів відносно бетонної оболонки.

4. Повторні навантаження незначно, але все ж впливають на величину руйнівної сили висмикування стержнів залежно від співвідношення їх жорсткостей.

\section{References}

1. Xolmyansky`j M.M. Kontakt armaturd s betonom. - M.: Strojy`zdat, 1981. - $184 \mathrm{c}$.

2. Chapyuk O.S. Doslidzhennya vply`vu povtorny`x navantazhen`rizny`x rivniv na mezhu zcheplennya armaturnogo prokatu klasu A500S z betonom / O.S. Chapyuk // Resursoekonomni materialy`, konstrukciyi, budivli ta sporudy`: Zbirny`k naukovy`x pracz`. - Rivne: NUVGP, 2009. - Vy`pusk 18. - S. 359 - 365.

3. Baby`ch Ye.M. Doslidzhennya zcheplennya armaturnogo prokatu serpovy`dnogo profilyu $\mathrm{z}$ betonom pry` odnorazovomu i povtornomu vy`tyaganni / Ye.M.Baby`ch, B.A. Vavry`nyuk, O.S. Chapyuk // Visny`k ODABA. - Odesa, 2009. - Vy`pusk 35. - S. 18-24.

4. Chapyuk O.S. Xaraktery`sty`ka napruzheno-deformovanogo stanu zcheplennya z betonom armatury` serpovy`dnogo profilyu / Mistobuduvannya ta tery 'torial'ne planuvannya: Nauk.-texn. zbirny`k K., KNUBA, 2014. - Vy`p. 54. - S. 461-467

\section{Список використаних джерел}

1. Холмянский М.М. Контакт арматуры с бетоном. - М.: Стройиздат, 1981. - 184 c.

2. Чапюк О.С. Дослідження впливу повторних навантажень різних рівнів на межу зчеплення арматурного прокату класу А500C 3 бетоном / О.С. Чапюк // Ресурсоекономні матеріали, конструкції, будівлі та споруди: Збірник наукових праць. - Рівне: НУВГП, 2009. - Випуск 18. - С. $359-365$.

3. Бабич С.М. Дослідження зчеплення арматурного прокату серповидного профілю з бетоном при одноразовому і повторному витяганні / Є.М.Бабич, Б.А. Вавринюк, О.С. Чапюк // Вісник ОДАБА. - Одеса, 2009. - Випуск 35. - С. 18-24.

4. Чапюк О.С. Характеристика напружено-деформованого стану зчеплення 3 бетоном арматури серповидного профілю / Містобудування та територіальне планування: Наук.-техн. збірник - К., КНУБА, 2014. - Вип. 54. - С. 461-467 